\title{
A PRÁTICA DO KITESURF E O UNIVERSO DA PRESERVAÇÃO AMBIENTAL
}

Recebido em: $11 / 12 / 2012$
Aceito em: $01 / 02 / 2012$

\author{
Angélica Brasileiro Lucena ${ }^{1}$ \\ Universidade Federal da Paraíba \\ João Pessoa - Paraíba - Brasil \\ Priscilla Pinto Costa da Silva ${ }^{2}$ \\ Faculdade Maurício de Nassau \\ Universidade Federal da Paraíba \\ João Pessoa - Paraíba - Brasil \\ Maria Dilma Simões Brasileiro ${ }^{3}$ \\ Universidade Federal da Paraíba \\ João Pessoa - Paraíba - Brasil
}

RESUMO: Este estudo tem como objetivo compreender a percepção dos praticantes de kitesurf sobre a relação entre a prática deste esporte e a preservação ambiental. Trata-se de uma pesquisa de abordagem qualitativa, realizada com 15 praticantes de kitesurf, em João Pessoa/PB. O instrumento utilizado foi à entrevista semiestruturada, analisadas por meio da técnica de Análise de Conteúdo. Os resultados apontam que a prática do kitesurf contribui para as vivências psicoemocionais, assim como para uma sensibilização ambiental, favorecendo tanto a preservação ambiental, quanto as questões socioeconômicas do lugar de prática. Aponta-se assim para uma estreita relação entre a prática do kitesurf e a preservação ambiental, embora nos discursos também se constate que esta relação necessita de um trabalho de consciência e responsabilidade coletiva, despertando esta problemática não somente para os praticantes de kitesurf, mas para toda a sociedade civil e os setores público e privado.

PALAVRAS CHAVE: Meio Ambiente. Atividade Motora. Natureza.

\section{KITESURF PRACTICE AND ENVIRONMENTAL PRESERVATION}

ABSTRACT: This study served to understand the perception of kitesurfers about the relationship between this sport and the environmental protection. It can be characterized

\footnotetext{
${ }^{1}$ Graduada em Educação Física pela Universidade Federal da Paraíba.

${ }^{2}$ Professora de Educação Física da Faculdade Maurício de Nassau. Professora de Educação Física da Universidade Federal da Paraíba. Membro do LAESTUS/CNPQ/UFPB

${ }^{3}$ Professora de Educação Física da Universidade Federal da Paraíba. Líder do LAESTUS/CNPQ/UFPB
} 
as a qualitative study, with 15 kitesurfers in João Pessoa/PB. In order to collect data, a semi-structured interview was utilized, whose results were analyzed through the Content Analysis method. This study revealed that the practice of kitesurf contributes to experiences psychoemotional, as to an environmental awareness, encouraging environmental preservation, as the socioeconomic issues of the place where it is practiced. Furthermore, this study points to a close relationship between kitesurf practice and environmental preservation, although the speeches found that this relationship needs to be worked through a sense of consciousness and collective responsibility, sharing this issue not only to the kitesurfers, but to all civilian society and the public and private sectors.

KEYWORDS: Environment. Motor Activity. Nature.

\section{INTRODUÇÃO}

O kitesurf consiste em uma prática náutica que depende da ação de três comandos: propulsão, direção e equilíbrio. Este esporte, que é uma combinação do surf, windsurf e wakeboard (BERNEIRA, et al., 2011), para ser praticado, precisa da sintonia desses três comandos com o praticante, além de condições climáticas favoráveis. Rios, lagos e mar são ambientes propícios para a prática deste esporte, desde que tenham, em média, ventos de aproximadamente 12 nós. Por ter condições climáticas privilegiadas, a prática do kitesurf é favorecida no litoral brasileiro (PAIXÃO; COSTA, 2009). Este fato tem contribuído para a crescente popularidade deste esporte no país.

Os instrumentos necessários para a prática do kitesurf consistem basicamente de uma prancha de windsurf tracionada por um parapente, que permite manobras na água e no ar (PETERSEN, et al., 2005). Neste sentido, por se diferenciar de outras atividades náuticas, para a prática do kitesurf se faz necessário a utilização de uma prancha combinada com a força de grandes e controláveis pipas para sua propulsão sobre a água. A pipa de kitesurf apresenta grande poder de tração, sendo possível atingir grandes velocidades nos deslocamentos, com salto de até 30 pés fora da água, sem a necessidade de ondas (HASENBAUER, 2008). 
O kitesurf forma parte das Atividades Físicas de Aventura na Natureza (AFANs) (BETRÁN; BETRÁN, 1995; BÉTRAN, 2003). As AFANs congregam qualidades como desafio, espontaneidade e impulsividade, podendo proporcionar aos praticantes, novas perspectivas de agir, pensar e comportar-se no cotidiano, construindo uma interligação entre o ser humano e o ambiente natural. Ao mesmo tempo, estas práticas envolvem a performance do ambiente e o locus do corpo (CATER; CLOKE, 2007). Este tipo de esporte, como aponta o estudo de Holyfield; Jonas; Zajicek, et al. (2005), promove o engajamento voluntário e incerto, em que as emoções são intensas.

O equilíbrio entre o corpo, a mente e natureza que submerge nas práticas de aventura, conduz ao sentimento de sensibilização e preservação ambiental (SILVA; FREITAS, 2010). Nesta mesma direção Bruhns (2000, 2006, 2009) aponta que, o cenário da natureza permite sensibilizar os sujeitos, entretanto, são necessárias várias vivências para despertar o aspecto sensibilizador nos praticantes. Em adicional, estudos realizados discutem a necessidade de se promover uma educação para a preservação ambiental, assim como para as AFANs (SILVA; CHAO, 2011; BARROS; DINES, 2000), com o intuito de diminuir os impactos negativos causados nos ambientes de práticas e a valorização dos impactos positivos.

Diante deste cenário e com a crescente popularização da prática do kitesurf, torna-se necessário estudar a prática deste esporte a luz da questão ambiental, buscando compreender o universo que envolve este esporte e as relações com o ambiente natural. Desta forma, este estudo tem como objetivo compreender a percepção dos praticantes de kitesurf sobre a relação entre a prática deste esporte e a preservação ambiental.

\section{METODOLOGIA}


O presente estudo caracteriza-se como uma pesquisa de campo, uma vez que permite ao observador aprofundar e ampliar o conhecimento sobre a temática analisada, e oportuniza vivenciar experiências diretas com a conjuntura do estudo, permitindo conhecer novas interpretações e conceitos sobre determinada realidade (BANKS, 2009). Este tipo de metodologia aproximar-se do fenômeno a ser estudado e possibilita ao pesquisador conhecer e estabelecer experiências no campo pesquisado.

Os sujeitos desta pesquisa foram 15 praticantes de kitesurf, que praticam este esporte na Praia do Bessa na cidade de João Pessoa/PB. Por não apresentar um número considerável do gênero feminino praticando esse esporte, os participantes foram apenas do gênero masculino, com idade entre 20 a 45 anos, que praticam o esporte há seis meses ou mais.

Os instrumentos utilizados para coletar os dados foram um Roteiro de Entrevista Semiestruturada e um Diário de Campo. Estes instrumentos permitem eficácia nas respostas e oportunizam o aprofundamento de determinado tema (COHEN; MANION; MORRISON, et al., 2000; DELGADO; GUTIÉRREZ, 1995). A entrevista seguiu os critérios estabelecidos por Henderson (1991), iniciando pelas perguntas gerais, como o interesse em iniciar a prática do kitesurf, seguindo para as questões mais específicas, relacionadas com as transformações sobre a percepção das questões ambientais que a prática do kitesurf trouxe para os sujeitos entrevistados. Como recursos para registro das informações foi utilizado um Diário de Campo e um gravador, que auxiliaram na coleta dos dados na Praia do Bessa - João Pessoa/PB. As entrevistas foram realizadas no turno da manhã, por haver um maior número de praticantes, no mês de maio de 2011. Todos os participantes da pesquisa assinaram o Termo de Consentimento Livre e Esclarecido. 
As análises das entrevistas e informações do Diário de Campo foram realizadas por meio da Análise de Conteúdo de Bardin (2011), por ser uma técnica de análise que dá suporte às análises do material coletado, por meio de procedimentos sistêmicos de descrição dos conteúdos.

Foram respeitadas as diretrizes regulamentadas pela Resolução n ${ }^{\circ}$ 196/96 do Conselho Nacional de Saúde/MS, sendo o projeto aprovado pelo Comitê de Ética em Pesquisa com seres humanos do Hospital Universitário Lauro Wanderley CEP/HULW, com o registro de número 194/11 e CAAE 0734.0.000.126-11.

\section{RESULTADOS E DISCUSSÃO}

A prática do kitesurf pode despertar comportamentos de preocupação com a natureza, podendo assim contribuir para a promoção da preservação ambiental. Com um olhar à luz deste contexto, os resultados deste estudo conduziram para três categorias analíticas: a) Motivações e adesão à prática do kitesurf; b) Impactos ambientais na prática de kitesurf; e c) Preservação ambiental e o comportamento dos praticantes de kitesurf no contexto social. Para a apresentação dos dados, utilizou-se a enumeração de 1 a 15, como forma de preservar a identidade dos sujeitos participantes do estudo.

\section{A adesão à prática do kitesurf}

A prática do kitesurf é realizada em meio pouco usual e em situações climáticas inconstantes, o que caracteriza a riqueza na quantidade de informações advindas da natureza, juntamente com a prática deste esporte. Tais características são semelhantes às práticas de vela, como o windsurf, laser e dingue, como apresentam estudos destas modalidades (FERNANDES, et al., 2007; ALLEN; DE JONG, 2006). Este contexto de prática torna também este tipo de esporte desafiador, e que exige momentos de 
superação. Contudo, a escolha por esta atividade não se restringe a idade, sexo ou ser portador de alguma deficiência, podendo ser apreciada por qualquer indivíduo, por sua fácil adaptação.

Estas características destes esportes influenciaram nos motivos que conduziram os sujeitos deste estudo a escolherem o kitesurf. Para os entrevistados, o interesse pelo kitesurf surgiu por meio de familiares que já o praticavam ou por convites de amigos kitesurfistas, como o relatado pelo entrevistado 4, que foi motivado por "um amigo meu que começou a praticar e depois resolvi praticar também”. Além dos amigos, a família também influencia na adesão à prática deste esporte, como afirma o entrevistado 6, ao relatar que "meu filho já praticavae resolvi praticar também". A adesão às AFANs por influência de familiares e amigos também foi constatado nos estudos de Amaral e Dias (2008) e Souza (2003) com surfistas.

Os dados analisados também apontam que a maioria dos entrevistados praticava o surf, antes de ingressar no kitesurf. Isso pode ser consequência de ambos os esportes apresentarem características semelhantes, como o fato da utilização da prancha no mar em suas práticas. Associado a prática anterior do surf, as condições climáticas da cidade de João Pessoa também favorece a prática do kitesurf, como aponta o entrevistado 1 : "Eu surfava antes, mas o período sem ondas era muito extenso e tinha ondas muito pequenas. A gente tinha que viajar muito. E com o kite não". Analisando os discursos dos entrevistados pode-se afirmar que as condições climáticas de uma região são determinantes na adesão da prática de uma determinada AFAN.

Outros aspectos que foram destacados pelos entrevistados pela adesão ao kitesurf, são os fatores psicoemocionais que são despertados por meios das AFANs. As sensações vivenciadas durante a prática de kitesurf estão presentes nos discursos dos 
entrevistados como bastante positivas, por estarem associadas ao prazer, a liberdade e paz de espírito. Neste sentido, o entrevistado 15 aponta que sente "uma sensação de liberdade quando estou no mar. Eu sempre curti esportes náuticos. É uma liberdade total. O vento, a água batendo no rosto... É bacana”. Estas sensações também são observadas nos estudos de outras AFANs, como no voo livre apresentado por Pimentel (2008), no montanhismo estudado por Monteiro (2006), na canoagem analisada por Lavoura; Schwartz; Machado, (2008) e no rapel estudado por Silva e Chao (2011). Sobre o kitesurf Zhang; Helander; Drury (1996) relatam que há uma percepção subjetiva de conforto, indicando bem-estar e relaxamento, por ser influenciada por fatores que apresentam interação entre a prática e o praticante, intermediada pelos fatores ambientais e humanos.

Os autores citados ainda apontam que, o contato com a natureza por meio das AFANs desperta sensações positivas, quando os praticantes atingem o objetivo da prática. Neste contexto, os discursos dos entrevistados do presente estudo revelam que o sentido de reencontro com a natureza proporciona tranquilidade aos praticantes, ao mesmo tempo em que transmite uma sensação de liberdade e uma ânsia desuperação dos obstáculos naturais, ao encontro da vertigem.

Além dos aspectos psicoemocionais, está presente também nos discursos dos entrevistados, a busca pela prática do kitesurf com objetivo de saúde, visto os benefícios que promovem esta prática para o corpo e a mente. Esta relação, entre a promoção da saúde e as AFANs, também é discutida por Rosa e Vaisberg (2002) e Franchi e Montenegro Junior (2005), que apontam melhorias nas sensações de bem-estar, disposição, melhorando a saúde em geral. Neste sentido, o entrevistado 3 afirma que, por meio da prática do kitesurf, consegiu um melhor preparo físico e melhor resistência. 
O entrevistado 14 também considerou melhoria na saúde física e mental, além de ressaltar que quando "saio do trabalho estressado, venho praticar kitesurf e quando saio do mar, fico renovado". No que se refere aos sentimentos de alívio e superação de tensões e estresses, as AFANs podem dar sentido e significado à própria vida (LE BRETON, 2009).

Os dados obtidos apontam, portanto, que os sujeitos praticam o kitesurf em busca de um sentimento de liberdade e desafio, que se sintam capazes de superar obstáculos, de aliviar o estresse do cotidiano, além de cuidar da saúde e do condicionamento físico. Em adicional, os praticantes também procuram superar seus medos e novos desafios encontrados em ambientes incertos.

\section{Impactos ambientais da prática do kitesurf}

A percepção dos praticantes sobre os possíveis impactos ambientais provocados pela prática de kitesurf está relacionada aosimpactos positivos e negativos que o kitesurf pode provocar ao meio ambiente. É crescente o interesse pelas questões relacionadas às AFANs e a preservação ambiental. Compreender esse universo contribuirá no entendimento da relação entre os praticantes das AFANs, mais especificamente do Kitesurf, e as questões ambientais.

Os estudos de Paixão, Costa e Gabriel (2009) e Garayeb, Silva e Meireles (2005) apresentam os impactos ambientais que vem aumentando em função do crescimento de práticas das AFANs, tornando uma problemática socioambiental. Nesta direção, no discurso dos entrevistados deste estudo constata-se o importante papel dos praticantes de kitesurf, na busca da preservação ambiental. Entretanto, os discursos apontam também que, para os entrevistados, este tipo de esporte não causa impacto ao meio ambiente, como foi relatado pelo entrevistado 13, ao afirmar que este esporte não 
provoca danos ao ambiente natural e "quem pratica, procura preservar o meio ambiente". Na perspectiva destes praticantes, constata-se uma relação linear entre a prática do kitesurf e a preservação ambiental, pois, desde esta perspectiva, o simples fato de praticar um esporte na natureza como o kitesurf, a preservação ambiental já é uma consequência natural.

É aceitável que os praticantes do kitesurf queiram resguardar o esporte que lhes traz satisfação. Entretanto, autores como Bahia e Sampaio (2007) e Silva e Chao (2011) apontam que existem impactos negativos causados pelas AFANs. Dentre os principais impactos negativos, os autores ressaltam a falta de organização dos responsáveis pelas práticas, a falta de educação ambiental e conscientização dos praticantes. Paixão, Costa e Gabriel (2009) interpretam que os impactos positivos ou negativos vão depender da qualidade da intervenção desenvolvida no espaço e da conscientização dos praticantes. Diante deste contexto, as intervenções educativas podem contribuir na sensibilização e trazer uma transformação consciente do uso dos espaços naturais pelos praticantes.

Ao se tratar dos possíveis impactos ambientais positivos proporcionados pela prática do kitesurf, no discurso de todos os entrevistados está presente a colaboração desta prática para a promoção da educação ambiental, como relata o entrevistado 9, quando ressalta que existe a "conscientização dos praticantes e banhistas sobre a importância da higienização das praias e dos ambientes naturais”. Um dado que merece destaque nestes discursos se refere à percepção dos entrevistados, quanto ao grau de escolaridade e o nível socioeconômico dos praticantes. Para os sujeitos deste estudo, as variáveis socioculturais determinam os discursos e as ações referentes à preservação ambiental, ou seja, quanto maior o nível socioeconômico e a escolaridade, maior a consciência na preservação ambiental. Corroborando com a percepção dos 
entrevistados, Maroun e Vieira (2007) encontraram em seus estudos que o nível socioeconômico e cultural dos praticantes de AFANs é um dos condicionantes que reflete na conscientização para a preservação ambiental. Neste sentido, aponta-se que não só a prática do kitesurf contribui para a preservação ambiental, mas o nível socioeconômico, cultural e educacional são também fatores condicionantes para esta conscientização.

Outro achado que se destaca no discurso dos entrevistados é a influência que eles acreditam que os praticantes de kitesurf exercem sobre a população. Desde a perspectiva dos mesmos, as atitudes e comportamentos dos praticantes do kitesurf acabam influenciando positivamente nas ações da população, em relação à preservação do ambiente natural. O estudo de Paixão, Costa e Gabriel (2009) faz referência a essa conscientização ambiental presente nos praticantes de AFANs e citam os impactos positivos proporcionados por tais práticas, como a melhoria na infraestrutura do lugar, a possibilidade de renda para a população próxima das localidades de práticas, a promoção da qualidade de vida da população, entre outras. Além desses aspectos, Lundgren, Brorsson e Osvalder (2012) ressaltam a importância da interpretação dos códigos do meio ambiente, por meio dos seus símbolos e signos, na prática do kitesurf. Esta interpretação, segundo os autores, auxilia não só na realização da prática, mas também na segurança do praticante.

As práticas de aventura podem ser analisadas, portanto, a partir de duas vertentes, ou seja, a primeira diz respeito aos impactos negativos e a segunda recai sobre os impactos positivos das referidas práticas em relação ao meio ambiente. Com base nos resultados deste estudo, bem como na literatura pesquisada, as AFANs apresentam a 
possibilidade de trabalhar a conscientização e a educação ambiental dos praticantes desses esportes na natureza.

\section{Preservação ambiental e o comportamento dos praticantes de kitesurf no contexto social}

O significado da preservação ambiental para os praticantes de kitesurf e a percepção dos mesmos em relação à atuação do poder público e das empresas privadas, faz referência ao empenho dos governantes e empresários em defesa das questões ambientais. Os entrevistados apontam que são poucas as ações promovidas, sendo necessários mais estímulos dos órgãos públicos e empresas privadas: "Eu acho super pouco. Você olha aqui a praia e não vê quase lixeiras" (Entrevistado 4). O entrevistado 9 sugere "levar uma sacolinha no carro, para não jogar lixo na rua", e o entrevistado 11 critica o poder público, ao afirmar que "se eles quisessem, poderiam realizar mais manifestações de conscientização".

Nesta direção, o estudo de Borges (2009) constata a falta de continuidade no planejamento e apoio de projetos por parte do setor público e privado. Para este autor, os setores, tanto o público quanto o privado, iniciam projetos para o benefício da comunidade, mas não demonstram interesse para que esses projetos obtenham sucesso e alcancem os objetivos traçados. Esta perspectiva também está presente nos discursos deste estudo, quanto os entrevistados enfatizam que as empresas poderiam realizar mais ações em benefício do meio ambiente e da população local, além de realizar eventos que conscientizem a população sobre a importância da preservação ambiental.

O estudo de Borges (2009) também aponta a dificuldade de manter programas públicos com a comunidade, por falta de apoio financeiro. Este fato remete à análise de que os programas e/ou projetos iniciados em benefício de um desenvolvimento 
sustentável, quando existem, não são prioritários e tampouco apresentam condições que perdurem, por limitação do apoio financeiro. Associado ao financiamento, também se constata a falta de gestores competentes para esses programas e/ou projetos, que priorizem um planejamento estratégico comum sistema de avaliação. Desde o setor privado, os programas e projetos só são implantados quando o lucro é assegurado, seja de forma direta ou indireta, como por meio do marketing associado à responsabilidade ambiental da empresa.

Entretanto, a problemática ambiental não é de responsabilidade apenas do setor público e privado. A sociedade civil também tem compromisso e responsabilidade socioambiental. Neste sentido, as grandes e pequenas atitudes do cotidiano das pessoas são as que geram ações de impacto positivo ao meio ambiente, como relata o entrevistado 14:

Eu quando estou dirigindo evito jogar lixo pela janela do veículo [...] e na praia também. Quando vejo alguém jogar latinhas no chão eu procuro recolher e, dependendo da pessoa, eu vou lá e dou uns toques, tipo: 'não joga o lixo aí não. Tem uma lixeira logo ali. Isso vai para dentro do mar, ai fica tudo poluído'.

Nos discursos destes entrevistados, constata-se a preocupação com a questão do lixo e com os problemas por ele acarretados. Assim mesmo, nos discursos também está presente a preservação da praia, ambiente de prática do kitesurf, e uma preocupação com as questões sociais em geral. As análises apontam que os entrevistados atribuem a si mesmo, a responsabilidade de conscientizar a população em relação à importância da limpeza das praias e à preservação da natureza. Resultados similares também foram encontrados por Maroun e Vieira (2007). No estudo destes autores, os praticantes de AFANs tinham responsabilidade de alertar a população sobre a degradação ambiental 
no local em que a prática esportiva era realizada, além de buscarem manter o ambiente preservado.

Sobre a contribuição das empresas privadas para a preservação ambiental, o entrevistado 3 afirma que "as empresas deveriam procurar conscientizar as camadas da sociedade". Para este entrevistado, a TV aberta e as redes sociais seriam fortes aliadas neste processo de conscientização ambiental. Para o entrevistado 7, "as empresas deveriam se preocupar com suas instalações físicas. Se estão respeitando as normas [...] ou até mesmo poluindo algum rio que passe por perto ou até o mar".

Estes discursos corroboram com os escritos de Matias (2008), que apresentam a possibilidade das empresas criarem alternativas para a preservação ambiental. Neste sentido, as empresas que organizam eventos de kitesurf devem assumir o compromisso político e socioambiental na organização das práticas e competições deste esporte. A obediência às normas ambientais e socioeconômicas por parte das empresas tende a melhorar a qualidade ambiental e socioeconômica nas zonas próximas aos locais de prática, promovendo, por consequência, qualidade ambiental e de vida para a população do lugar, além da possibilidade de mais adeptos às AFANs.

Neste sentido, as grandes empresas e corporações têm uma relação próxima com a promoção consciente das AFANs, tanto como patrocinadores, quanto ao apoio às empresas pequenas e microempresas que oferecem os serviços e possibilitam estas práticas. Portanto, as empresas têm um papel fundamental na responsabilidade ambiental, já que os praticantes de AFANs se utilizam de serviços e produtos de muitas dessas empresas e que também têm os espaços naturais como cenário para suas atividades empresariais.

\section{CONSIDERAÇÕES FINAIS}


O estudo buscou investigar a percepção dos praticantes de kitesurf sobre a relação entre a prática deste esporte e a preservação ambiental. Os resultados apontam que a prática do kitesurf é recente no litoral da Paraíba e adesão a esta prática veio por meio de outras modalidades, especialmente do surfe. Os motivos que levaram aos entrevistados a praticarem o kitesurf foram a busca por sentimentos de satisfação, liberdade e alívio da pressão do cotidiano, bem como a busca de novos desafios e a melhoria na qualidade de vida, além do contato com a natureza. Os discursos dos entrevistados também apontam seus familiares e amigos como principais influências para a adesão da prática do esporte.

Existe no discurso dos entrevistados uma preocupação presente, e crescente, quanto às questões ambientais. Entretanto, desde uma leitura linear dos entrevistados, os discursos apontam que a prática do kitesurf não traz impacto negativo ao meio ambiente. Por outro lado, os impactos positivos são apresentados pelos entrevistados, com ênfase na conscientização e interesse dos praticantes em colaborar com a preservação ambiental. Neste sentido, os praticantes de kitesurf atribuem ao nível socioeconômico, cultural e educacional elevados dos praticantes desta modalidade, os motivos que favorecem a conscientização ambiental.

Os entrevistados julgam ineficazes e escassas as intervenções do poder público e das empresas privadas na relação entre a prática das AFANs e a preservação ambiental e socioeconômica das pessoas dos lugares de prática, ressaltando que os representantes públicos poderiam realizar mais campanhas de intervenção nestes âmbitos. Quanto ao setor privado, os entrevistados apresentam uma falta de preocupação deste setor com os espaços construídos, os serviços e produtos oferecidos, mostrando pouco respeito e comprometimento com as questões ambientais. Contudo, os praticantes de kitesurf 
também atribuem à sociedade civil responsabilidade de preservação ambiental, colaborando e disseminando a ideia de um meio ambiente digno e sustentável.

\section{REFERÊNCIAS}

ALLEN, J. B.; DE JONG, M. R. Sailing and sports medicine: A literature review. British Journal of Sports Medicine, Londres, v. 40, n. 7, p. 587-593, 2006.

AMARAL, A. V.; DIAS, C. A. Da praia para o mar: motivos à adesão e à prática do surfe. Licere, Belo Horizonte, v. 11, n. 3, p. 1-22, 2008.

BAHIA, M. C. SAMPAIO, T. M. V. Lazer - meio ambiente: em busca das atitudes vivenciadas nos esportes de aventura. Revista Brasileira de Ciências do Esporte, Campinas, v. 28, n. 3, 2007. Disponível em: www.cbce.tempsite.ws/revista/index.php/RBCE/article/download/30/37. Acesso em: 24 fev. 2011.

BANKS, M. Dados visuais para pesquisa qualitativa. Tradução J. Fonseca. Porto Alegre: Artmed, 2009.

BARDIN, L. Análise de conteúdo. Tradução Luís Antero Reto e Augusto Pinheiro. São Paulo: Edições 70, 2011.

BARROS, M. I. A.; DINES, M. Mínimo impacto em áreas naturais: uma mudança de atitude. In: SERRANO, C. (Org.) A Educação Pelas Pedras: ecoturismo e educação ambiental. São Paulo: Chronos, 2000. p. 47-84.

BERNEIRA, J. O., et al. Incidência e característica das lesões em praticantes de kitesurf. Revista Brasileira de Cineantropometria \& Desempenho Humano, Florianópolis, v. 13, n. 3, p.195-201, 2011

BETRÁN, J. O. Rumo a um novo conceito de ócio ativo e turismo na Espanha: as atividades físicas de aventura na natureza. In: MARINHO, A.; BRUHNS, H. T. Turismo, lazer e natureza. Barueri: Manole, 2003.

; BETRÁN, A. O. La crisis de la modernidad y el advenimiento de la posmodernidad: el deporte y las prácticas físicas alternativas en el tiempo de ocio activo. APUNTS. Educación Física y deportes, n. 41, p.10-29, 1995.

BORGES, E., V., Projetos esportivos públicos e privados no processo de inclusão social de crianças e adolescentes: um perfil da $26^{\mathrm{a}}$ secretaria de desenvolvimento regional, 2009. Dissertação (Mestrado). Universidade do Contestado - UnC. Disponível em:

<http://www.cni.unc.br/unc2009/editais/arquivos/Mestrado/DISSERTACAO_DE_MES TRADO-ELCIO_V._BORGES.pdf $>$. Acesso em: 08 Jun. 2011. 
BRUHNS, H. T. Esporte e natureza: o aprendizado da experimentação. In: SERRANO, C. (Org.) A Educação Pelas Pedras: ecoturismo e educação ambiental. São Paulo: Chronos, 2000. p. 25-46.

Ecoturismo e caminhada: na trilha das idéias. In: MARINHO, A.;

Viagens, Lazer e Esporte: o espaço da natureza. Barueri: Manole, 2006. p. 27-42.

A busca pela natureza: turismo e aventura. Barueri: Manole, 2009.

CATER, C.; CLOKE, P. Bodies in action. Anthropology Today, Estados Unidos, v. 23, n.6, p.13-16, 2007.

COHEN, L.; MANION, L.; MORRISON, K. R. B. Research methods in education. 5. ed. Londres: Routledge, 2000.

DELGADO, J.; GUTIÉRREZ, J. Métodos y Técnicas Cualitativas de Investigación en Ciencias Sociales. Madrid: Editorial Sínteses, 1995.

FERNANDES, H. et al. Perfil Psicológico e sua importância no rendimento em vela. Revista motricidade, Portugal, v.3, n.3, p. 24-32, 2007.

FRANCHI, K. M. B.; MONTENEGRO JUNIOR, R. M. Atividade Física: uma necessidade para a boa saúde na terceira idade. Revista Brasileira em Promoção da Saúde, Fortaleza, v. 16, n. 3, p 152-156, 2005.

GARAYEB, A.; SILVA, E. V.; MEIRELES, A. J. A. Impactos ambientais e propostas de manejo sustentável para a planície flúvio-marinha do Rio Pacoti - Fortaleza/Ceará. Sociedade \& Natureza, Uberlândia, v.17, n.33, 2005. Disponível em: <http://www.seer.ufu.br/index.php/sociedadenatureza/article/viewFile/9210/5672>

Acesso em: 25 nov. 2010.

HASENBAUER, BRIAN. Kiteboarding in Texas? Competitor Texas, v. 5, n.7, p.44, 2008.Disponível

em: <http://web.ebscohost.com/ehost/pdfviewer/pdfviewer?sid=bca4aeff-9052-429998b5-956722448e0f\%40sessionmgr13\&vid=1\&hid=17 > Acesso em: 20 jul. 2011.

HENDERSON, K. Dimensions of choice: a qualitative approach to recreation parks and leisure research. State College, PA: Venture Publishing, 1991.

HOLYFIELD, L.; JONAS, L.; ZAJICEK, A. Adventure without risk is like Disneyland. In: LYNG, S. (Ed.). Edgework: The sociology of risk-taking. New York: Routledge, 2005.

LAVOURA, T. N.; SCHWARTZ, G. M.; MACHADO, A. A. Aspectos emocionais da prática de atividades de aventura na natureza: a (re)educação dos sentidos. Revista Brasileira de Educação Física e Esporte, São Paulo, v.22, n.2, p.119-12, 2008. Disponível em: <http://www.usp.br/eef/rbefe/v22n22008/3_RBEFE_v22_n2_2008_p119.pdf> Acesso em: 19 nov. 2011. 
LE BRETON, D. Condutas de risco: dos jogos de morte ao jogo de viver. Tradução Lólio Lourenço de Oliveira. Campinas: Autores Associados, 2009.

LUNDGREN, L.; BRORSSON, S.; OSVALDER, A. Comfort aspects important for the performance and safety of kitesurfing. Work: A Journal of Prevention, Assessment and Rehabilitation, v. 41, p. 1221-1225, 2012. Disponível em: $<$ http://iospress.metapress.com/content/0674540044318g5r/fulltext.pdf>. Acesso em: 23 nov. 2012.

MAROUN, K.; VIEIRA, V.Impactos ambientais positivos são possíveis nos esportes praticados em ambientes naturais? Efdesportes, Revista Digital. Buenos Aires Ano 12. N.108, 2007. Disponível em: http://www.efdeportes.com/efd108/impactosambientais-positivos-nos-esportes-praticados-em-ambientes-naturais.htm. Acesso em: 26 Mar. 2011.

MATIAS, M. Os efeitos dos megaeventos esportivos nas cidades.Turismo \& Sociedade, Curitiba, v. 1, n.2, p. 175-198, 2008. Disponível em: http://ojs.c3sl.ufpr.br/ojs2/index.php/turismo/article/viewFile/12934/8732. Acesso em: 19 jan. 2012.

MONTEIRO, S. V. Lazer, natureza e amizade: formas de subjetivação na modernidade tardia. In: MARINHO, A.; BRUHNS, H. T. Viagens, Lazer e Esporte: o espaço da natureza. Barueri: Manole, 2006.

PAIXÃO, J. A.; COSTA, V. L. M. Esporte de aventura e turismo de aventura: aproximações e distanciamentos. Revista Digital, Buenos Aires - Año 14 - N. 139, 2009. Disponível em: http://www.efdeportes.com/efd139/esporte-de-aventura-eturismo-de-aventura.htm . Acesso em: 21 jul. 2011.

PAIXÃO, J. A.; COSTA, V. L. M.; GABRIEL, R. E. C. D. Esporte de aventura e ambiente natural: dimensão preservacional na sociedade de consumo. Revista Motriz, Rio Claro, v.15, n.2, p.367-373, 2009. Disponível em: <http://www.efdeportes.com/efd139/esporte-de-aventura-e-turismo-de-aventura.htm> Acesso em: 23out 2010

PETERSEN, W., et al. Verletzungenbeimkitesurfen. Orthopade, Montag, v.34, n.5, p. 419-425, 2005.

PIMENTEL, G. G. A. Ritos e risco na prática do vôo livre. Movimento, Porto Alegre, v.14, n. 3, p. 13-32, 2008.

ROSA, L. F. P. B.; VAISBERG, M. W. Influências do exercício na resposta imune. Revista Brasileira de Medicina do Esporte, São Paulo, v.8, n.4,p. 167-172, 2002. <http://www.scielo.br/pdf/rbme/v8n4/v8n4a06.pdf >. Acesso em: 20 dez. 2011.

SILVA, P. P. C.; FREITAS, C. M. S. M. Emoções e riscos nas práticas na natureza: uma revisão sistemática. Motriz, Rio Claro, v.16, n.1, p. 221-23, 2010.

SILVA, P. P. C.; CHAO, C. H. Práticas corporais na natureza: por uma educação ambiental. Revista da Educação Fisica/UEM, Maringá, v. 22, n.1, p. 89-97, 2011. 
SOUZA, A. M. "Evoluindo": mulheres surfistas na Praia Mole e Barra da Lagoa. 2003. Dissertação (Programa de Pós-Graduação em Antropologia Social) -Universidade Federal de Santa Catarina, Florianópolis, 2003.

ZHANG, L.; HELANDER, M. G.; DRURY, C. G. Identifying Factors of Comfort and Discomfort in Sitting. Human Factors: The Journal of the Human Factors and Ergonomics Society, v. 38, p. 377-389, 1996.

\section{Endereço das Autoras:}

Maria Dilma Simões Brasileiro

Universidade Federal da Paraíba (UFPB)

Centro de Ciências da Saúde (CCS)

Departamento de Educação Física (DEF)

Cidade Universitária João Pessoa - PB

58.051-900

Endereço Eletrônico: laprisci@gmail.com 